Case Report

\title{
VARIATIONS OF FORAMEN TRANSVERSARIUM IN ATLAS VERTEBRAE : A MORPHOLOGICAL STUDY WITH ITS CLINICAL SIGNIFICANCE
}

\author{
Qudusia Sultana ${ }^{1}$, Ramakrishna Avadhani ${ }^{2}$, Varalakshmi KL ${ }^{3}$, Shariff $\mathrm{MH}^{4} \&$ Blessina $^{5}$ \\ ${ }^{1,3}$ Assistant Professors, ${ }^{2}$ Professor \& Head, ${ }^{5}$ Post Graduate, Department of Anatomy, ${ }^{4}$ Associate Professor Department of \\ Pathology, Yenepoya M edical College, Deralakatte, M angalore, Karnataka, India. \\ Correspondence : \\ Qudusia Sultana \\ Assistant Professor, Department of Anatomy, Yenepoya Medical College, Deralakatte, Mangalore 575018, Karnataka, India \\ Mobile : +91 7899114567 E-mail : qudsia.shariff@yahoo.co.in
}

\section{Abstract:}

Introduction : The second part of the vertebral artery along with vertebral venous plexus and sympathetic plexus traverses through vicinity of foramen transversarium of atlas. Derangement of these structures in their course may be seen due to deformities, narrowing and presence of osteophytes in foramen transversarium.

Methods : Two hundred foramen transversarium of 100 atlas vertebrae were grossly studied for their variations.

Results : Out of hundred atlas vertebrae examined, we found that all the vertebrae had foramina transversaria. Absence of costal element was noticed in five atlas vertebrae. 2 of the vertebrae showed incomplete unilateral foramen transversarium, 3 vertebrae showed bilateral incomplete foramen, In 1 vertebra along with normal foramen transversarium, complete retroarticular foramen was observed on the left side and incomplete retroarticular foramen observed on the right side of the posterior arch. 4 vertebrae showed incomplete retroarticular foramen.

Conclusion : The increasing incidence of neck injuries and related syndromes necessitates the study of bony variations of the atlas vertebra and its transverse foramina. Due to the incomplete formation of the foramen transversarium the second part of vertebral artery is prone to be damaged easily during posterior cervical injuries and Surgeries. The bony bridges embracing the vertebral artery may be responsible for vertigo and cerebrovascular accidents hence the knowledge of such variations is important for Physicians, Otirhinolaryngologists, neurologists, Orthopaedicians and Radiologists.

Keywords : Vertebral artery, Atlas vertebra, Foramen Transversarium, Retroarticular foramen, Cerebrovascular accidents.

\section{Introduction :}

Atlas the first cervical vertebra supports the head. It is ring shaped; it has no body no spine, has a short anterior arch, a long posterior arch, two lateral masses and two long transverse processes projecting laterally from the lateral masses containing foramen transversarium, sometimes deficient leaving foramen transversarium incomplete. ${ }^{1}$

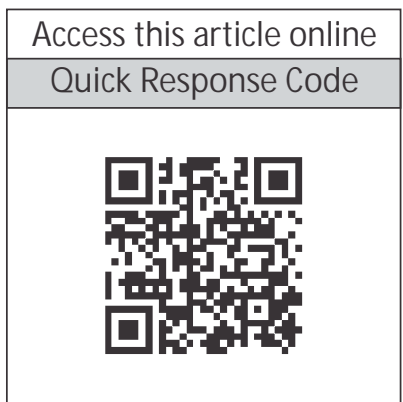

The second part of the vertebral artery traverses through vicinity of $\mathrm{C} 6-\mathrm{C} 1$ foramen transversarium along with vertebral venous plexus and sympathetic plexus, it then enters the foramen magnum and joins with the corresponding vertebral artery to form basilar artery. ${ }^{2}$

Derangement of these structures in their course is due to narrowing, deformities and presence of osteophytes in foramen transversarium which has been investigated by many authors. ${ }^{3}$

Many anatomical variations are observed in cervical and proximal thoracic vertebrae due to the intense transformation it undergoes during phylogeny. An Atlas vertebra differs in structure from other cervical vertebrae and it is also the most variable vertebrae in man.4Studies have been conducted by many authors on the variations in size, shape,incomplete or double foramen transversarium, but very few authors have studied about the variant of retroarticular foramen 5 which we have studied. 
In an atlas vertebra, the retroarticular foramen variant seen isformed by the bony outgrowth from the superior articular facet over the groove present on the posterior arch of atlas vertebrae. It is formed by ossification of the oblique ligament of atlas present at the inferior border of posterior atlantooccipital membrane .Existence of such foramen may cause compression on the artery during the extreme rotatory movements of the neck or manipulation of the cervical spine during surgeries, physiotherapy or exercises and cause vertebrobasilar ischemia which may lead to common symptoms like migraine, vertigo, diplopia, shoulder pain, neck pain or severe incidents of cerebrovascular incidents. ${ }^{7}$ Hence the increasing incidence of neck injuries and related syndromes necessitates the Physicians, Orthopaedicians, Otirhinolaryngologists, Neurosurgeons and Radiologists to know the bony variations of the atlas vertebra and its transverse foramina. ${ }^{8}$

\section{Methods:}

Hundred dry atlas vertebrae of unknown sex but of a South Indian population were obtained from the department of Anatomy and students of first year M BBS, Yenepoya M edical College. Broken atlases were excluded from the study. Presence, absence, incomplete foramen transversarium and retroarticular foramen were carefully looked for and the boundaries carefully noted in two hundred transverse processes of 100 atlas vertebrae.

\section{Results:}

Out of two hundred transverse processes of hundred atlas vertebrae examined, we found that all the vertebrae had foramina transversaria.

Absence of costal element was noticed in five atlas vertebrae 2 of the vertebrae showed incomplete unilateral foramen transversarium: Anterior margin of the foramen transversarium was absent on the right side in one case and posterior margin deficient on right side in another vertebra .In 3 vertebrae Anterior margin was absent bilaterally (Figure 1).

In 1 vertebra along with normal foramen transversarium, retroarticular foramen was observed on the left side and incomplete retroarticular foramen observed on the right side of the posterior arch(figure 2).

4 vertebrae showed incomplete retroarticular foramen: 3 on right side and 1 on left side.

Figure 1 : A, C unilateral and B, D, E bilateral incomplete foramen transversarium.

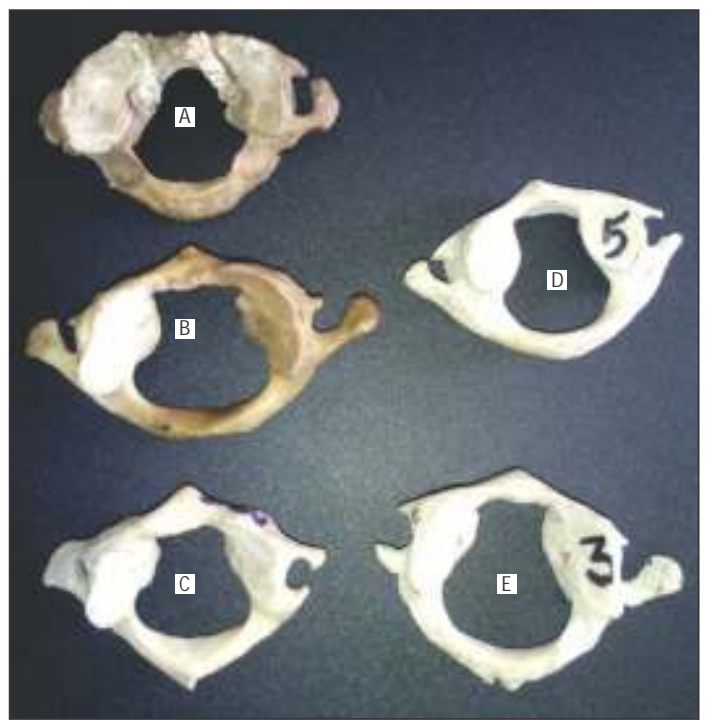

Figure 2 : complete and incomplete retroarticular canal.

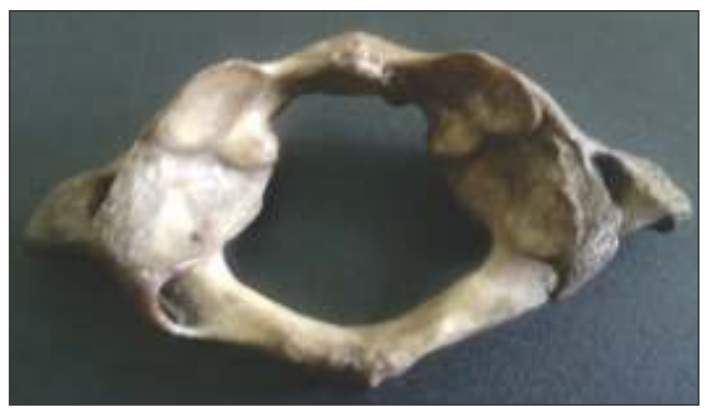

\section{Discussion :}

As atlas is among the three important constituents of craniovertebral junction it is clinically more important due to grooves and foramina in its posterior and lateral margins. ${ }^{9}$

M any authors have studied on different variations of Atlas vertebrae like deficient anterior arch, deficient posterior arch, retroarticular foramen, accessory foramen, incomplete foramen transversarium. ${ }^{4,5}$ Taitz in1978 reported absence of the transverse foramen at $\mathrm{C} 4$ and $\mathrm{C} 6$ vertebrae.10 Vasudeva and Kumar in 1995 reported unilateral absence of foramen transversarium on the left 
side of atlas.11 Nayak in 2007 observed bilateral absence of foramen transversarium.12 Seeema in 2013 found posterolateral vertebral tunnel on the left side of atlas.13 Zambare in 2011 studied fifty atlas vertebrae and found In $4 \%$ of cases complete and $12 \%$ cases incomplete ring. 2 Chauhan in 2013 studied fifty atlas vertebrae and found absence of costal element in seven vertebrae. ${ }^{5}$

The retroarticular foramen isformed due to the lateral growth of bone from superior articular facet to the posterior arch of atlas. It is formed by the ossification of the oblique ligament of the atlas which may be complete or incomplete. During the extreme rotatory movements the vertebral artery and the first cervical nerve passing through it can get compressed and may lead to vertebro-basilar insufficiency and many neurological symptoms. ${ }^{2}$

Some authors have found correlation between morphology of atlas with head and neck posture14 and others have stated that congenital defect and variations of atlas occur together and it is hereditary. ${ }^{15}$

Some authors said that potency of existing osteogenic cells in the region of craniovertebral junction is activated leading to formation of retroarticular canal and others believe that the pulsation of the vertebral artery itself could induce the bridging with ossification of oblique ligament of atlas. ${ }^{16}$

Clinical significance of such anatomical variations of the Foramen transversarium is useful for estimating changes in the vessels and accompanying nerves ${ }^{17}$ because vertebral

\section{References :}

1. Standring S. Gray's anatomy: the anatomical basis of clinical practice. 39th edn, Edinburgh: Elsevier Churchill Livingstone; 2005

2. Zambare BR, Reddy BB.The Retro-articular Ring Of Atlas and its Clinical Significance.Anatomica Karnataka 2011; Vol-5(2):74-76.

3. S RB, Neginhal DD. Variations in foramen transversarium of atlas vertebra: An osteological study in South Indians. Int J Res Health Sci [Internet]. 2014Jan31;2(1):224-8.

4. Wysocki J, Buhrowski M, Reymond J, Kwiastkowski J. Anatomical variants of the cervical vertebrae and the first thoracic vertebra in man. Folia M orpho (Warsz) 2003;62: 357-63.

5. Chauhan R, Khanna J. Absence of costal element of the foramen transversarium of atlas vertebrae. Int J Res M ed Sci. 2013; 1:66-8.

6. Mitchell $\mathrm{J}$. The incidence of the lateral bridge of the atlas vertebra. Anat. 1998;193(2):283-85.[PM C free article] [PubM ed]

7. Krishnamurthy A, Nayak SR, Khan S, Prabhu Latha V, Lakshmi A, et al. vessels are important factor in the formation of the Foramen transversarium, and variations in the presence and course of the vessels will be seen with the changes in foramen transversarium .It was also noted that tortousity of vertebral artery may cause bone erosion or obstruct the complete formation of the foramen transversarium. ${ }^{18}$

The occurrence of incomplete foramen transversarium can be confused with fractures and other anomalies and hence should be known to radiologists for accurate interpretation of radiographs and computed tomographic scans $\mathrm{s}^{4,19,20}$ and occurrence of retroarticular foramen can cause many vascular and neurological symptoms which should be kept in mind by treating Physicians and Surgeons and always think of variations in the atlas vertebrae as one of the possible cause.

\section{Conclusion:}

Anatomical variations of atlas especially in the bony bridges embracing the vertebral artery and first cervical nerve may be responsible for vertigo and many neurological disturbances and hence it is of clinical importance. Knowledge of such variations is important for Physicians, Otirhinolaryngologists, neurologists and Orthopaedicians. Due to the incomplete formation of the foramen transversarium the second part of vertebral artery may be dislodged and prone to get damaged easily during posterior cervical injuries. The knowledge of the variations on foramen transversarium is important for radiologists as they may misinterpret as fractures and operating surgeons to prevent the hazard of injury to the vertebral artery.

Arcuate foramen of atlas: incidence, phylogenetic and clinical significance. Romanian Journal of Morphology and Embryology. 2007;48(3):263-66.[PubM ed]

8. Agrawal D, M ohanty BB, Shetty S, Parija B, Hazary SK and Chinara PK. 2012. Variations in foramen transversarium: An osteological study in eastern India. Int J of current research 4(9):120-122

9. Hasan M, Shukla S, Siddiqui MS, Singh D. Posterolateral tunnels and ponticuli in human atlas vertebrae. J anat.2001; 199:339-343.

10. Taitz C, Nathan $\mathrm{H}$. Some observations on the posterior and lateral bridge of the atlas. Acta Anat (Basel) 1986; 127:212-7.

11. Vasudeva N, Kumar R.Absence of foramen transversarium in the human atlas vertebra: a case report. Acta Anat (Basel) 1995;152:230-3

12. Nayak BS. Bilateral absence of foramen transversarium in atlas vertebra: a case report. Neuroanatomy $2007 ; 6: 28-9$

13. Singh M, Mahajan A. M, MAHAJAN. A. A posterolateral vertebral 
artery tunnel of atlas vertebra-a case report. Int J Anat Var.2013; 6: $118-119$

14. Sandikcioglu M Skov S, Solow B. Atlas morphology in relation to craniofacial morphology and head posture. Eur J Orthod 16. 1994;(2): 96-103.

15. Li S, Li W, Sun J. Operative treatment forcervical vertigo caused by foramen arcuale. Zhonghua Wai Ke Za Zhi.1995; 33:137 - 139

16. Piplani M L, Singla R K, J S K. Bilateral Arcuate Foramen in a Human Atlas Vertebra - A Case Report. International Journal of Anatomy, Radiology and Surgery. 2013 Oct; Vol-2(3): 3-6

17. Kaya S, Yilmaz ND, Pusat S, Kural C, Kirik A, Izci Y.Double foramen transverseriam variation in ancient Byzantine cervical vertebrae: preliminary report of an anthropological study. Turk Neurosurg 21.2011; (4):534-8.

18. Hyyppa SE, Laasonen EM, Halonen V. Erosion of cervical vertebrae caused by elongated and tortuous vertebral arteries. Neuroradiology 1974; 7:49-51

19. Karau PB,Odula P. Some anatomical and morphometric observations in the foramina of the atlas among Kenyans. Anat J of Africa 2012; 2(1):61-66.

20. Chaudhari ML. Maheria PB,Bachuwar SP. Double Foramen Transversarium in CervicalVertebra: Morphology and Clinical importance. September 2013: Issue-8, Vol.-2, P.1084-1088 